\title{
Obesity, Diabetes mellitus and Methylenetetrahydrofolate reductase mutations: Deadly combinations? How to approach them?
}

\section{Journal of Diabetes and Endocrinology Research}

Research Article

Raul H. Morales-Borges

Integrative Optimal Health of Puerto Rico

\section{"Correspondence author}

Raul H. Morales-Borges

Integrative Optimal Health of Puerto Rico

29 Washington St. Suites \#105 \& 107

San Juan, PR 00907-1509

Tel

: 787-722-0412

Fax : :787-723-0554

Cel : :787-354-0758

E-mail : raul.morales.borges@gmail.com

Submitted : 20 Nov 2020 ; Published : 30 Nov 2020

\section{Introduction}

Obesity and diabetes mellitus (DM) are important independent risk factors for the development of cardiovascular disease (CVD). Obesity is the leading risk factor for type 2 diabetes. The Centers for Disease Control and Prevention report that $32 \%$ of white and 53\% of black women are obese. Women with a body mass index (BMI) of $30 \mathrm{~kg} / \mathrm{m}^{2}$ have a 28 times greater risk of developing diabetes than do women of normal weight. The risk of diabetes is 93 times greater if the BMI is $35 \mathrm{~kg} / \mathrm{m}^{2}$. The presence of DM can increase a woman's risk of heart disease 2-fold. In addition, the presence of diabetes overshadows the protective effects of the premenopausal state [1]. Obesity is common, serious, and costly. The prevalence of obesity was $39.8 \%$ and affected about 93.3 million of US adults in 2015-2016 [2]. The estimated annual medical cost of obesity in the United States was $\$ 147$ billion in 2008 US dollars; the medical cost for people who have obesity was $\$ 1,429$ higher than those of normal weight [3]. Regarding diabetes mellitus (DM), it's a major cause of blindness, kidney failure, heart attacks, stroke and lower limb amputation. In 2014, 8.5\% of adults aged 18 years and older had diabetes. In 2016, diabetes was the direct cause of 1.6 million deaths and in 2012 high blood glucose was the cause of another 2.2 million deaths [4].

The clustering of certain metabolic factors (e.g., abdominal obesity, dyslipidemia and elevated blood pressure), that define the metabolic syndrome (MS), has been documented to identify patients at increased risk for type $2 \mathrm{DM}$, as well as CVD and overall mortality $[5,6]$. The MS is a growing health problem worldwide with an estimated prevalence in developed countries of $25-35 \%$ in adults, in parallel with the increasing prevalence of obesity and diabetes [7].

An elevation of serum homocysteine level (Hcy) is generally accepted as an independent and graded risk factor for various pathologies, including vascular diseases, neural tube defects, Alzheimer disease, and pregnancy complications between others

[8].

Methylenetetrahydrofolate reductase (MTHFR) by catalyzing the conversion of 5,10 methylenetetrahydrofolate to 5-methyltetrahydrofolate, is a pivotal enzyme in folate metabolism that regulates the proportional usage of one-carbon units between methylation reactions and nucleic acid synthesis. The C677T MTHFR gene polymorphism results in a reduced specific MTHFR activity ( $34 \%$ residual activity in T677T, $71 \%$ residual activity in C677T relative to C677C) [9].

The MTHFR gene polymorphisms were also found to be associated with body mass index (BMI)-defined obesity and lean mass, sustaining a linkage of body mass index (BMI) and lean mass to chromosome $1 \mathrm{p} 36$, where the MTHFR gene is located $[10,11]$.

Cardiovascular disorders, obesity, type 2 diabetes, peripheral neuropathy, and others are related to high Hcy levels and MTHFR mutations so they are responsible of high morbidity and mortality globally. Many patients benefit from diet programs, exercises, genetic screening, serum Hcy levels, and folate supplementation to treat their condition inclusive as prevention. Studies involving a larger study population and different ethnic groups and genetic counseling are required.

\section{Evidence-Based Data}

Di Renzo, et al. performed a study where the examined the role of the C677T MTHFR gene polymorphism in the response to diet in the management of metabolic syndrome [9]. They investigated the body composition and metabolic factor changes after a hypocaloric balanced diet (HBD), in Italian obese women affected by metabolic syndrome (MS). Forty-four obese women affected by MS were eligible for the study. A HBD for 12 weeks was assigned. Study participation included a complete 
screening for dietary habits, anthropometry, body composition, blood biochemical markers and C677T MTHFR polymorphism genotyping. In the $81 \%$ of the total population a loss of Total Body Lean was observed. A significative loss $(\mathrm{p} \leq 0.05)$ of Total Body Lean was observed in the $47 \%$ of T (-) carriers and in the $53 \%$ of $\mathrm{T}(+)$ carriers. Their data provide the basis for personalized dietary recommendations based on the individual's genetic makeup and nutritional status. MTHFR genetic variations analysis would be an innovative tool for the nutritional assessment.

Pirozzi, et al. evaluated the frequencies of the angiotensin converting enzyme (ACE) gene insertion/deletion (I/D) and MTHFR gene C677T polymorphisms in obese patients with and without type 2 DM [12]. These polymorphisms were analysis by polymerase chain reaction in 125 patients with obesity, 47 (DM) and 78 (Control Group). No significant difference was found on comparing the DM and Control Groups in respect to the genotypic frequencies of the polymorphisms - (II: $13.3 \%$ vs. $12.0 \%$; ID: $37.8 \%$ vs. 37.3 ; DD: $48.9 \%$ vs. $50.7 \%$; CC: $36.2 \%$ vs. $39.0 \%$; CT: $46.8 \%$ vs. $49.3 \%$; TT: $17.0 \%$ vs. $11.7 \%$ ), and alleles (I: $32.2 \%$ vs. $30.7 \%$; D: $67.8 \%$ vs. $69.3 \%$; C: $59.6 \%$ vs. $63.6 \%$; T: $40.4 \%$ vs. $36.4 \%$ ) and their synergisms in the pathophysiology of T2DM. On analyzing the DM Group, there were no significant differences in the presence of complications. In this population of Brazilian obese patients, no correlation was found between the ACE and MTHFR polymorphisms in the development of T2DM. In the group with diabetes, there was also no relationship between these polymorphisms and comorbidities.

Gara, et al. studied 31 obese compared to 22 no obese children. Hcy level was assessed by fluorescence-immunoassay; folate and vitamin B12 by radioimmunoassay [13]. C677T and G80A mutations were detected using pyrosequencing. There were no differences in Hcy levels between obese and no obese, (10, $34 \pm$ $4,86 \mu \mathrm{moll} / 1 \mathrm{vs} 11,00 \pm 4,26 \mu \mathrm{moll} / \mathrm{l})$. They found no difference for the allelic frequencies of the C677T polymorphism (29.03\% vs $30.95 \%$ ) and of the G80A polymorphism (64.52\% vs 59.52 $\%)$. Mean levels of Hcy, folic acid and vitamin B12 were not significantly different according to MTHFR and RFC genotypes. They demonstrated no difference in Hcy, folates, vitamin B12 levels and allelic frequencies of C677T and G80A polymorphisms in MTHFR and RFC genes between obese and no obese Tunisian children. These two polymorphisms don't seem to have any impact on homocysteine, folate and vitamin B12 status in the two populations.

Regarding insulin resistance and obesity in adolescents related to MTHFR mutation, Frelut, et al. studied one-hundred and thirteen obese $\left(\mathrm{BMI}=39.1 \pm 6.4 \mathrm{~kg} / \mathrm{m}^{2}\right)$ adolescents aged $14.4 \pm 1.5$ years and information on growth obtained from individual health records was available at birth $(\mathrm{n}=107), 1(\mathrm{n}=102), 2(\mathrm{n}=106)$, $4(\mathrm{n}=91)$ and $8(\mathrm{n}=73)$ years of age [14]. Fifty-nine subjects were heterozygote $(\mathrm{CT}, 52.2 \%)$ and 8 were homozygote for the mutation (TT, 7.0\%). Birth weights were lower in TT (2.95 \pm 0.48 $\mathrm{kg}, \mathrm{p}=0.004)$ than in $\mathrm{CC}(3.34 \pm 0.43 \mathrm{~kg})$ and $\mathrm{CT}(3.38 \pm 0.50$ $\mathrm{kg}$ ) subjects, as well as birth lengths (CC: $0.50 \pm 0.02 \mathrm{~m}, \mathrm{CT}$ : $0.50 \pm 0.02 \mathrm{~m}$, TT: $0.47 \pm 0.03 \mathrm{~m}, \mathrm{p}=0.01)$. These differences persisted until 1 year of age. Median and mean fasting glycaemia were similar. Insulin levels were higher in TT (median: $26.4 \mathrm{UI} /$ $\mathrm{mL}$ ) than in $\mathrm{CC}$ (median: $15.0 \mathrm{UI} / \mathrm{mL}$ ) or $\mathrm{CT}$ (median: $16.0 \mathrm{UI} /$
$\mathrm{mL})(\mathrm{p}=0.017)$ subjects, as well as HOMA IR $(\mathrm{p}=0.04)$. Body composition, blood pressure, plasma lipids, homocysteine and leptin concentrations were similar among the three genotypes in both boys and girls. The common $677 \mathrm{C}->\mathrm{T}$ mutation seems therefore to represent a link between altered early growth and enhanced degree of insulin resistance that occurs later in obese adolescents.

Regarding diabetic patients, prevalence of the 2 heterozygous polymorphisms of the thermolabile MTHFR gene (CT and $\mathrm{AC})$ was encountered more commonly in patients with diabetes mellitus than in the healthy controls $\left(\mathrm{p}<10^{-3}\right)[15]$. Subjects who had significantly higher Hcy levels than the control subjects; however, there was no statistical difference in plasma Hcy values between carriers of mutant genotypes (CT/TT for C677T and AC/ CC for A1298C) and wild types (CC and AA) in patients with diabetes. Retinopathy was found to be a vascular complication in patients with either the $677 \mathrm{CT}$ or the $1298(\mathrm{AC}+\mathrm{CC})$ genotype more commonly than in those with the wild-type genotypes $\left(\mathrm{p}=0.003 ; \mathrm{OR}=3.2,95 \% \mathrm{CI}, 1.4\right.$ to $7.4 ; \mathrm{p}<10^{-3} ; \mathrm{OR}=5.9,95 \%$ CI, 2.7 to 13). Only patients who carry the A1298C mutation $(\mathrm{AC}+\mathrm{CC})$ are at risk for at least 1 complication $(\mathrm{p}=0.002)$. Double heterozygous mutants were at the greatest risk for retinopathy and for suffering at least 1 complication $\left(\mathrm{p}<10^{-3}\right)$.

Diabetic peripheral neuropathy (DPN) is also studied in MTHFR mutations. $\mathrm{Wu}$, et al. demonstrated that subgroup analysis by country indicated that the MTHFR $677 \mathrm{C}>$ T polymorphism may be the main risk factor for DPN in Turkey under four genetic models [16]. ACE D $>$ I mutation was correlated with DPN in Japanese and Pakistani populations in most groups. The relationships of MTHFR $677 \mathrm{C}>$ T and ACE I/D polymorphisms with DPN patients presented in this meta-analysis support the view that the MTHFR and ACE genes might play an important role in the development of DPN. Meanwhile, Jiménez-Ramírez, et al. carried out a study and sixty-seven percent (67\%) of participants carry at least one of these MTHFR polymorphisms [17]. No deviations from HardyWeinberg equilibrium were detected. The genotype and allele frequencies showed statistically significant differences between participants and controls $(\mathrm{p}<0.0001$ and $\mathrm{p}=0.03$, respectively). Results suggest that $1298 \mathrm{~A}>\mathrm{C}$ but not $677 \mathrm{C}>\mathrm{T}$ is associated with DPN susceptibility in this cohort $(\mathrm{p}=0.018)$. Different patterns of allelic dissimilarities are observed when comparing our cohort vs. the three parental ancestries. After sorting individuals by their carrier status, no significant associations were observed between these genetic variants (independently or combined) and any of the biochemical markers (HbAlc, folate, vitamin B12, homocysteine). They concluded that the prevalence of major MTHFR variants in Puerto Rican patients with DM is first time ever reported. The study provides further evidence on the use of this genetic marker as an independent risk factor for DPN.

\section{Conclusions and Recommendations}

Obesity, Diabetes, and MTHFR polymorphisms are linked together and carries a high risk for the society globally as well as higher costs in healthcare. From disease management and prevention perspective, these studies have demonstrated that genetic screening for the polymorphisms, serum folate and Hcy levels, and aggressive nutritional evaluation and management 
should be applied to decrease the morbidity and mortality with this combinations. Also, important actions for risk factor management in the primary prevention of cardiovascular disease in healthy individuals are needed.

Personalized lifestyle medicine can provide solutions to chronic health , in particularly obesity, diabetes, metabolic syndrome, and diseases related to MTHFR mutations, by harnessing innovative and evolving technologies based on recent discoveries in genomics, epigenetics, systems biology, life and behavioral sciences, and diagnostics and clinical medicine. A comprehensive, personalized approach to medicine is required to promote the safety of therapeutics and reduce the cost of chronic disease. Personalized lifestyle medicine may provide a novel means of addressing a patient's health by empowering them with information they need to regain control of their health.

\section{References}

1. Barnes AS (2011) The epidemic of obesity and diabetes: trends and treatments. Tex Heart Inst J 38: 142-144.

2. Hales CM, Carroll MD, Fryar CD, Ogden CL (2017) Prevalence of obesity among adults and youth: United States, 2015-2016. NCHS data brief, no 288. Hyattsville, MD: National Center for Health Statistics.

3. Finkelstein EA, Trogdon JG, Cohen JW, Dietz W (2009) Annual Medical Spending Attributable to Obesity: PayerAnd Service-Specific Estimates. Health Affairs 28: w822-w831.

4. Saran R, Li Y, Robinson B, et al. (2015) US Renal Data System 2014 Annual Data Report: Epidemiology of Kidney Disease in the United States. Am J Kidney Dis 66: S1-S305.

5. Janghorbani M, Amini M (2012) Associations of hip circumference and height with incidence of type 2 diabetes: the Isfahan diabetes prevention study. Acta Diabetol 49: S107-114.

6. Wannamethee SG, Shaper AG, Lennon L, Morris RW (2005) Metabolic syndrome vs Framingham Risk Score for prediction of coronary heart disease, stroke, and type 2 diabetes mellitus. Arch Intern Med 165: 2644-2650.

7. Ervin RB (2009) Prevalence of metabolic syndrome among adults 20 years of age and over, by sex, age, race and ethnicity, and body mass index: United States, 20032006. Natl Health Stat Report 13: 1-7.

8. Kluijtmans LAJ, Young IS, Boreham CA, Murray L, McMaster D, McNulty H, Strain JJ, McPartlin J, Scott JM, Whitehead AS (2003) Genetic and nutritional factors contributing to hyperhomocysteinemia in young adults. Blood 101: 2483-2488.

9. Di Renzo L, Marsella LT, Sarlo F, et al. (2014) C677T gene polymorphism of MTHFR and metabolic syndrome: response to dietary intervention. J Transl Med 12: 329.
10. Liu X, Zhao LJ, Liu YJ, Xiong DH, Recker RR, Deng HW (2008) The MTHFR gene polymorphism is associated with lean body mass but not fat body mass. Hum Genet 123: 189-196.

11. Norris JM, Langefeld CD, Scherzinger AL, Rich SS, Bookman E, Beck SR, Saad MF, HaVner SM, Bergman RN, Bowden DW, Wagenknecht LE (2005) Quantitative trait loci for abdominal fat and BMI in Hispanic-Americans and African-Americans: the IRAS family study. Int J Obes (Lond) 29: 67-77.

12. Pirozzi FF, Belini Junior E, Okumura JV, Salvarani M, Bonini-Domingos CR, Ruiz MA (2018) The relationship between of ACE I/D and the MTHFR C677T polymorphisms in the pathophysiology of type 2 diabetes mellitus in a population of Brazilian obese patients. Arch Endocrinol Metab 62: 21-26.

13. Gara S, Ochi H, Chango A, Najjar L, Feki M, B chir F, Kaabachi N, Ben Becher S, Boukthir S, Abdennebi M (2011) C677t polymorphism of MTHFR and G80A polymorphism of RFC genes and their relation with homocysteine levels in obese Tunisian children. Tunis Med 89: 565-568.

14. Frelut ML, Nicolas JP, Guilland JC, de Courcy GP (2011) Methylenetetrahydrofolate reductase 677 C-> T polymorphism: a link between birth weight and insulin resistance in obese adolescents. Int J Pediatr Obes 6: e312317.

15. Fekih-Mrissa N, Mrad M, Ibrahim H, Akremi I, Sayeh A, Jaidane A, Ouertani H, Zidi B, Gritli N (2017) Methylenetetrahydrofolate Reductase (MTHFR) (C677T and A1298C) Polymorphisms and Vascular Complications in Patients with Type 2 Diabetes. Can J Diabetes 41: 366371.

16. Wu S, Han Y, Hu Q, Zhang X, Cui G, Li Z, Guan Y (2017) Effects of Common Polymorphisms in the MTHFR and ACE Genes on Diabetic Peripheral Neuropathy Progression: a Meta-Analysis. Mol Neurobiol 54: 24352444.

17. Jiménez-Ramírez FJ, Castro LM, Ortiz C, Concepción J, Renta JY, Morales-Borges RH, Miranda-Massari JR, Duconge J (2017) Role of treatment-modifying MTHFR677C $>\mathrm{T}$ and $1298 \mathrm{~A}>\mathrm{C}$ polymorphisms in metformin-treated Puerto Rican patients with type-2 diabetes mellitus and peripheral neuropathy. Drug Metab Pers Ther 32: 23-32.

Copyright: (C2019 Raul H. Morales-Borges. This is an open-access article distributed under the terms of the Creative Commons Attribution License, which permits unrestricted use, distribution, and reproduction in any medium, provided the original author and source are credited. 